\title{
Produtividade de capim Tifton 85 sob irrigação e doses de nitrogênio
}

\author{
Eder P. Gomes ${ }^{1}$, Max E. Rickli², Ulysses Cecato ${ }^{3}$, Camila V. Vieira ${ }^{4}$, \\ Juliano G. Sapia ${ }^{5}$ \& Arthur C. Sanches ${ }^{6}$
}

\section{Palavras-chave: \\ composição botânica \\ matéria seca \\ relação folha/colmo \\ Cynodon spp.}

\begin{abstract}
R E S U M O
O trabalho foi conduzido em uma propriedade de atividade leiteira no município de Xambrê, região Noroeste do Paraná, no período de março de 2011 a fevereiro de 2012 com o objetivo de avaliar a produtividade e a composição botânica do capim Tifton 85 com e sem irrigação sob doses de nitrogênio. As parcelas experimentais foram implantadas com delineamento de blocos ao acaso com e sem irrigação e as subparcelas por meio de quatro doses de nitrogênio: 0, 20, 40 e $60 \mathrm{~kg} \mathrm{ha}^{-1}$ por ciclo de pastejo, com quatro repetições. $\mathrm{A}$ produtividade em matéria seca (MS) foi maior sob irrigação crescendo de forma linear à adubação nitrogenada. $\mathrm{Na}$ dose de $60 \mathrm{~kg} \mathrm{~N} \mathrm{ha}^{-1}$ foram obtidas produtividades iguais a 39279 e $27826 \mathrm{~kg} \mathrm{MS} \mathrm{ha}^{-1}$, com e sem irrigação, respectivamente. A relação folha colmo não foi afetada pela irrigação. A média geral do percentual de material morto com e sem irrigação, foi igual a 13 e $17 \%$, respectivamente.
\end{abstract}

\section{Key words:}

botanical composition

dry matter

leaf/stem ratio

Cynodon spp.

\section{Yield of Tifton 85 grass under irrigation and nitrogen doses}

\begin{abstract}
A B S T R A C T
The study was conducted on a dairy farm in the municipality of Xambre, Northwest region of Parana, in the period from March 2011 to February 2012 to evaluate the yield and botanical composition of Tifton 85 with and without irrigation under nitrogen doses. The experimental plots were implanted in completely randomized blocks with and without irrigation and subplots through four nitrogen levels: $0,20,40$ and $60 \mathrm{~kg} \mathrm{ha}^{-1}$ per grazing cycle, with four replications. The yield in dry matter (DM) was higher under irrigation, responding linearly to increasing nitrogen fertilization. At a dose of $60 \mathrm{~kg} \mathrm{~N} \mathrm{ha}^{-1}$ yields of 39279 and $27826 \mathrm{~kg} \mathrm{DM} \mathrm{ha}^{-1}$ were obtained, with and without irrigation, respectively. The leaf stem ratio was not affected by irrigation. The overall mean percentage of dead material with and without irrigation was equal to 13 and $17 \%$, respectively.
\end{abstract}

Protocolo 030-2014 - 29/01/2014 • Aprovado em 28/11/2014 • Publicado em 02/03/2015

${ }^{1}$ FCA/UFGD. Dourados, MS. E-mail: edergomes@ufgd.edu.br (Autor correspondente)

${ }^{2}$ DMV/UEM. Umuarama, PR. E-mail: ricklimax@hotmail.com

${ }^{3}$ DZO/UEM. Maringá, PR. E-mail: ulyssescecato@gmail.com

${ }^{4}$ FEAGRI/UNICAMP. Campinas, SP. E-mail: camilavianav@hotmail.com

${ }^{5}$ DCA/UEM. Umuarama, PR. E-mail: guilhermesapia@hotmail.com

${ }^{6}$ DEB/ESALQ-USP. Piracicaba, SP. E-mail: arthur_carniato@hotmail.com 


\section{INTRODUÇÃo}

Por se tratar de um país de clima tropical, o potencial produtivo das pastagens no Brasil é elevado, podendo exercer redução significativa no custo de produção da pecuária (Corrêa \& Santos, 2003); entretanto, a taxa de lotação do rebanho bovino nacional ainda é baixa, da ordem de 1,2 animal por hectare (ABIPEC, 2014).

Entre outros fatores, a adubação nitrogenada pode ser usada para promover a intensificação da produção a pasto (Alvim et al., 1999). O uso da irrigação também vem crescendo como forma de aumentar a produção de biomassa forrageira porém vale ressaltar que a capacidade produtiva das pastagens está condicionada também a fatores climáticos, principalmente temperatura e fotoperíodo (Alencar et al., 2009).

Nas regiões Centro-Sul, onde há queda significativa da produção de forragem durante o inverno (Balieiro Neto et al., 2007), a irrigação, apesar de não ser capaz de alterar a situação, pode ser utilizada para diminuir a estacionalidade (Benedetti et al., 2000; Rassini, 2004).

Além da irrigação a utilização de forrageiras subtropicais pode ser usada para atenuar a estacionalidade, destacando-se os capins do gênero Cynodon pelo elevado potencial produtivo e nutritivo (Fagundes et al., 1999), possuindo temperatura basal inferior, da ordem de $12^{\circ} \mathrm{C}$ (Corrêa \& Santos, 2006). Rocha et al. (2002) verificaram, avaliando três cultivares de Cynodon, que o Tifton 85 foi o mais produtivo.

Alguns resultados de pesquisas vêm demonstrando que o acúmulo médio anual em matéria seca (MS) capim Tifton 85 sem irrigação é inferior ao irrigado e está compreendido numa faixa entre 50 e $90 \mathrm{~kg} \mathrm{MS} \mathrm{ha}^{-1} \mathrm{~d}^{-1}$ (Alvim et al., 1999; Fagundes et al., 1999; Pinto et al., 2001; Brink et al., 2004; Marsalis et al., 2007) enquanto sob irrigação a matéria seca acumulada oscila de 105 a $125 \mathrm{~kg} \mathrm{MS} \mathrm{ha}^{-1} \mathrm{~d}^{-1}$ (Marcelino et al.,2003; Rodrigues et al., 2005; Fonseca et al., 2007; Bow \& Muir, 2010; Nogueira et al., 2013) podendo chegar a $170 \mathrm{~kg} \mathrm{MS} \mathrm{ha}^{-1} \mathrm{~d}^{-1}$ (Aguiar et al., 2006).

Em referência à adubação nitrogenada, a produtividade de Tifton 85 responde, em geral, de forma linear crescente (Alvim et al., 1999; Rocha et al., 2002; Quaresma et al., 2011). No entanto, em experimento com doses de nitrogênio e irrigação, Marcelino et al. (2003) verificaram que produtividadede Tifton 85 somente foi linear crescente enquanto a tensão de água no solo foi mantida abaixo de $35 \mathrm{kPa}$. Ao contrário, Rodrigues et al. (2005) não constataram interação entre lâminas de irrigação e doses de nitrogênio na produtividade de Tifton 85 .

Este trabalho tem, por objetivo, avaliar a produtividade e a composição botânica do capim Tifton 85 (Cynodon spp.) sob irrigação e doses de nitrogênio, na região Noroeste do Paraná.

\section{Material e Métodos}

O trabalho foi conduzido em uma propriedade de atividade leiteira, localizada em uma área de Latossolo Vermelho Distrófico típico (EMBRAPA, 2006), textura arenosa, no município de Xambrê, PR ( $23^{\circ} 44^{\prime}$ de latitude Sul, 53 $28^{\prime}$ de longitude Oeste e $418 \mathrm{~m}$ de altitude), no período de março de 2011 a fevereiro de 2012. O solo da área experimental na camada de 0 - 0,20 m apresentava as seguintes características químicas: $\mathrm{pH}\left(\mathrm{CaCl}_{2}\right)$ de 5,3, $\mathrm{P}$ igual a $3,2 \mathrm{mg} \mathrm{dm}^{-3}, \mathrm{H}^{+}+\mathrm{Al}^{3+}$, $\mathrm{Al}^{3+}, \mathrm{Ca}^{2+}+\mathrm{Mg}^{2}$ e $\mathrm{K}^{+}$iguais a 2,74, 0, 1,88 e $0,05 \mathrm{cmol}_{\mathrm{c}} \mathrm{dm}^{-3}$.

Segundo a classificação de Köppen, o clima da região é do tipo Cfa. No período experimental a temperatura média foi de $22,9^{\circ} \mathrm{C}$, com precipitação pluviométrica acumulada de 1567,4 $\mathrm{mm}$. No trimestre mais frio, maio, junho e julho, os valores médios de temperatura média e temperatura mínima foram iguais a 18,8 e $12,8^{\circ} \mathrm{C}$, respectivamente (Figura 1 ).

Em 16 de outubro de 2010 foram aplicados, na área a lanço, $1160 \mathrm{~kg} \mathrm{ha}^{-1}$ de calcário calcítico (PRNT $\left.=75 \%\right)$. Realizou-se o preparo do solo com aração profunda $(0-0,40 \mathrm{~m})$ com arado de 03 discos e gradagem $(0-0,20 \mathrm{~m})$ por meio de grade aradora de 16 discos; posteriormente, realizou-se adubação de base com $120 \mathrm{~kg} \mathrm{ha}^{-1} \mathrm{de}_{2} \mathrm{O}_{5}$ na forma de superfosfato triplo, juntamente com o transplante das mudas de capim Tifton 85, com espaçamento de $0,50 \mathrm{~m}$, distribuídas em sulcos abertos pelo sulcador de linha (tração animal) a 0,20 m de profundidade.

Após brotação das mudas foram realizadas adubações com $200 \mathrm{~kg}_{\text {de }} \mathrm{N} \mathrm{ha}^{-1}$ na forma de ureia e $100 \mathrm{~kg} \mathrm{ha}^{-1}$ de $\mathrm{K}_{2} \mathrm{O}$ na forma de cloreto de potássio, parceladas em cinco vezes sendo a primeira aos 21 dias após transplante (DAT) e depois a cada 30 dias. Após a última parcela da adubação, em 5 de março de 2011, liberou-se a área para pastejo e se fez, em seguida, a uniformização da altura do capim por meio de roçada a $12 \mathrm{~cm}$.

Durante o período pré-experimental (16/10/2010 a 05/03/2011), o controle de plantas daninhas ocorreu por meio de retiradas manuais e controle químico utilizando-se $0,4 \mathrm{~L}$ de Volcane ${ }^{\circledast}$ em associação com $0,4 \mathrm{~L}$ de Diuron ${ }^{\circledR}$, parcelado em duas vezes, 15 e 45 DAT, com solução de $0,01 \mathrm{~L} \mathrm{~L}^{-1}$.

O experimento foi implantado em delineamento de blocos ao acaso com esquema de de parcelas subdivididas. As parcelas foram constituídas pela irrigação (presença e ausência) e as subparcelas por meio de 4 doses de nitrogênio (N): 0, 20, 40 e $60 \mathrm{~kg} \mathrm{ha}^{-1}$ por ciclo de pastejo, na forma de sulfato de amônio, com quatro repetições. A adubação potássica foi feita na relação de 0,7 entre $\mathrm{K}_{2} \mathrm{O}$ e $\mathrm{N}$.

A irrigação ocorreu por meio de um sistema de aspersão com espaçamento de $15 \mathrm{~m}$ por $15 \mathrm{~m}$, coincidente com a área da parcela experimental. O manejo de irrigação foi realizado de forma suplementar, com turno de rega fixo (quarta-feira e sábado) a partir da leitura de tensiômetros instalados a 0,15

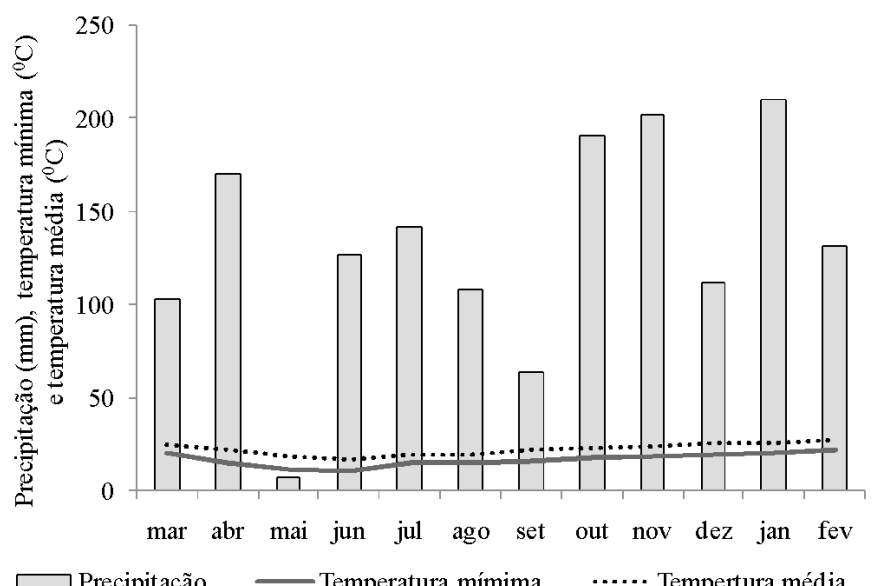

Figura 1. Valores de precipitação, temperatura mínima e temperatura média de março/2011 a fevereiro/2012 
$m$ de profundidade (metade da profundidade efetiva). As irrigações ocorriam somente quando a tensão de água no solo era superior a $6 \mathrm{kPa}$ (considerada tensão na capacidade de campo). Os valores de tensão de água no solo ocorridos durante o ciclo experimental podem ser visualizados na Figura 2.

Antes de iniciar o experimento retiraram-se três amostras indeformadas na diagonal da área experimental a $0,15 \mathrm{~m}$ (representando a camada de 0 a $0,30 \mathrm{~m}$ ); essas amostras foram saturadas e posteriormente submetidas à câmara de pressão. As umidades correspondentes foram determinadas por termo gravimetria (padrão estufa); na Tabela 1 se encontram os valores originais de pressão e umidade volumétrica.

Na elaboração da curva de retenção considerou-se pressão igual à tensão de água no solo (mesmo valor em módulo). O ajuste foi realizado pela equação de Genuchten (1980) (Figura 3).

A lâmina de irrigação acumulada durante o período experimental foi de $837,5 \mathrm{~mm}$, distribuída por meio de 77 eventos, dentre os quais $16,18,23$ e 20 eventos ocorridos no outono, inverno, primavera e verão, respectivamente. Nessas estações as lâminas acumuladas somaram 121,1, 152,3, 256,6

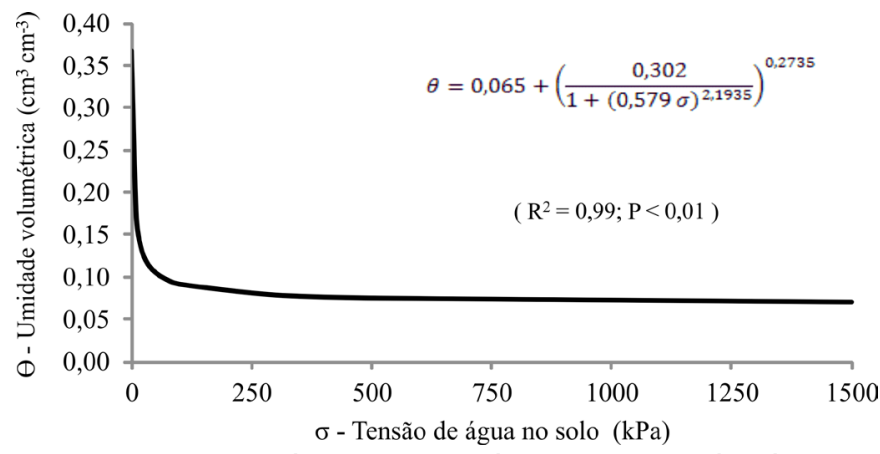

Figura 3. Curva de retenção de água no solo da área experimental, na camada de 0 a $0,30 \mathrm{~m}$

e $307,5 \mathrm{~mm}$, respectivamente. As precipitações por meio de chuvas, nas respectivas estações foram iguais a 322,3, 313,3, 430 e 428,4 mm. Na Figura 4 tem-se a distribuição dos valores da precipitação e irrigação durante o período experimental.

A altura de pastejo do capim Tifton 85 foi medida uma vez por semana e as coletas foram realizadas nos momentos em que referidas alturas superaram o valor de $30 \mathrm{~cm}$ nas parcelas
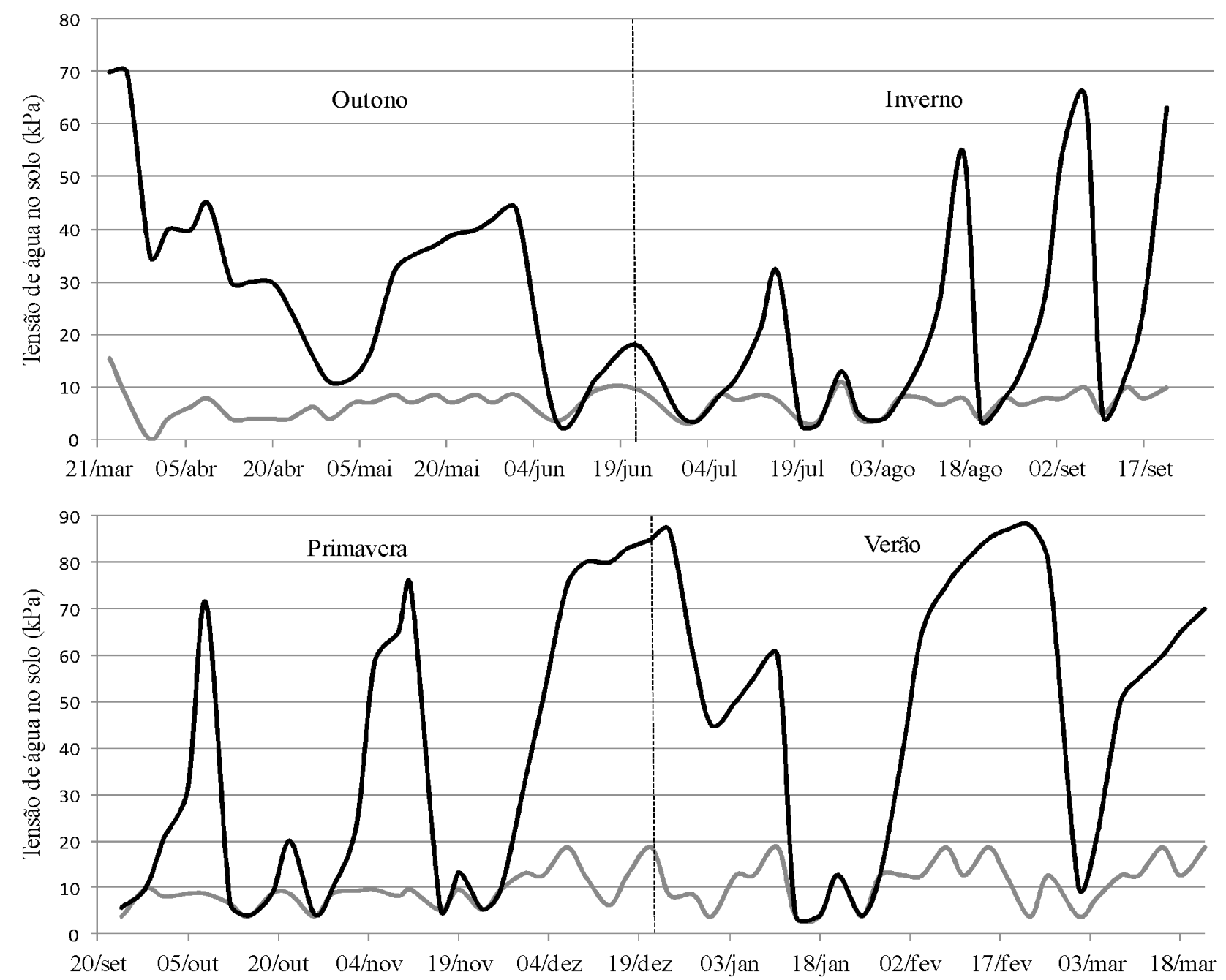

Com irrigação - Sem irrigação

Figura 2. Valores de tensão de água no solo em área de capim Tifton-85 com e sem irrigação

Tabela 1. Valores de tensão de água no solo e umidade volumétrica da área experimental na camada de 0 a $0,30 \mathrm{~m}$

\begin{tabular}{|c|c|c|c|c|c|c|c|c|c|c|c|}
\hline $\mathrm{O}(\mathrm{kPa})$ & 0 & 10 & 20 & 30 & 40 & 50 & 70 & 100 & 300 & 500 & 1500 \\
\hline ade volumétrica $\left(\mathrm{cm}^{3} \mathrm{~cm}^{-3}\right)$ & 0,367 & 0,169 & 0,139 & 0,120 & 0,105 & 0,101 & 0,098 & 0,095 & 0,083 & 0,076 & 0,070 \\
\hline
\end{tabular}




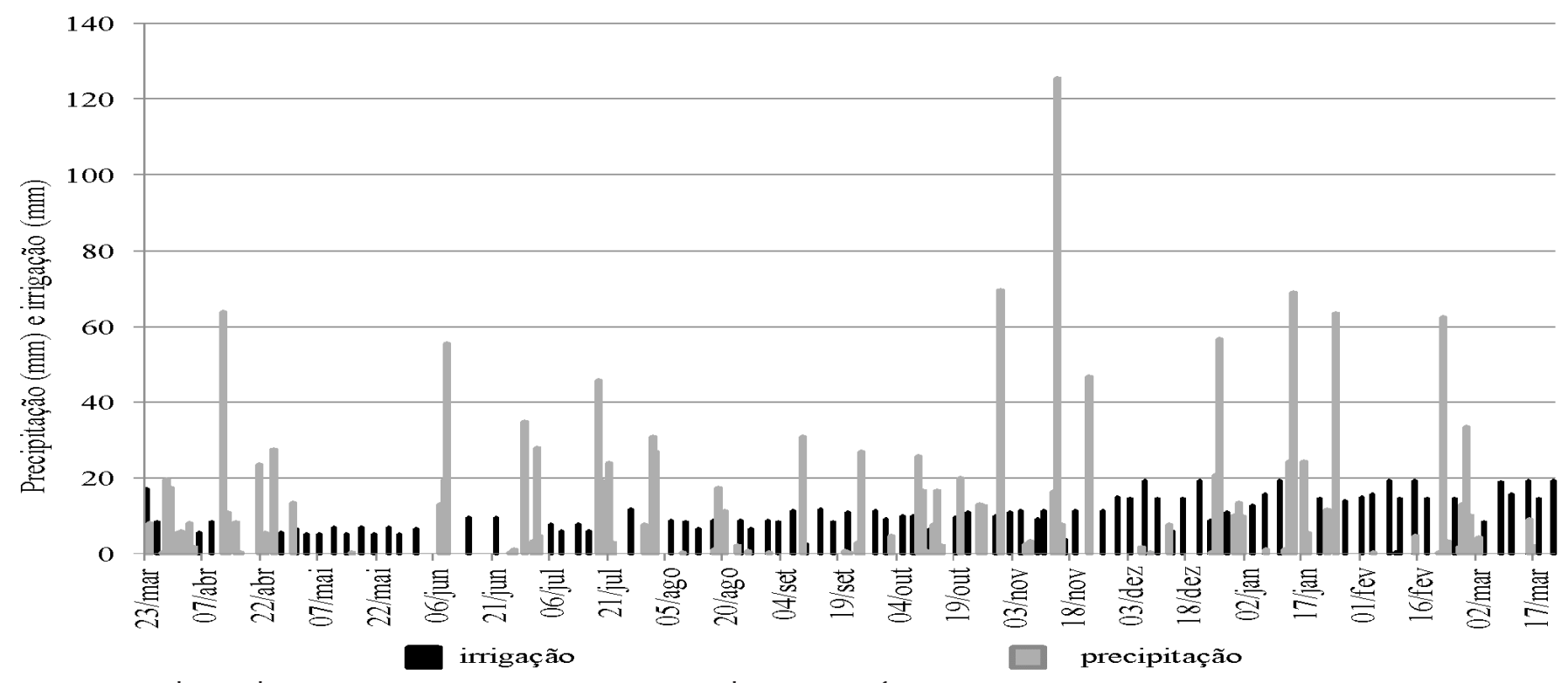

Figura 4. Valores de precipitação e irrigação em área de capim Tifton-85


para todos os tratamentos). Nessas ocasiões foi coletada, nos centros das parcelas, uma área de $1 \mathrm{~m}^{2}$, realizando-se corte a $12 \mathrm{~cm}$. Após as coletas toda a área experimental era rebaixada também a $12 \mathrm{~cm}$ por meio do pastejo dos animais. Nas parcelas irrigadas obtiveram-se 10 ciclos de pastejo e nas não irrigadas, 7 ciclos, o que equivale às doses de nitrogênio iguais 0,200 , 400 e 600 e $0,140,280$ e $420 \mathrm{~kg} \mathrm{ha}^{-1}$ ano $^{-1}$, respectivamente.

As coletas de forragem foram encaminhadas para separação botânica (material morto, folha e colmo) e posteriormente seca em estufa de circulação forçada a $65^{\circ} \mathrm{C}$ por $72 \mathrm{~h}$ para determinação da matéria seca e das variáveis de produtividade:

$$
\mathrm{PROD}=\mathrm{MSF}+\mathrm{MSC}+\mathrm{MSM}
$$

em que:

PROD - produtividade total de matéria seca, $\mathrm{kg} \mathrm{ha}^{-1}$

MSF - massa seca de folhas, $\mathrm{kg} \mathrm{ha}^{-1}$

MSC - massa seca de colmos, $\mathrm{kg} \mathrm{ha}^{-1}$

MSM - massa seca de material morto, $\mathrm{kg} \mathrm{ha}^{-1}$

$$
\mathrm{PROD}_{\mathrm{ES}}=\mathrm{MSF}_{\mathrm{ES}}+\mathrm{MSC}_{\mathrm{ES}}+\mathrm{MSM}_{\mathrm{ES}}
$$

em que: $\mathrm{kg} \mathrm{ha}{ }^{-1}$

$\mathrm{PROD}_{\mathrm{ES}}$ - produtividade total de matéria seca na entressafra,

$\mathrm{MSF}_{\mathrm{ES}}$ - massa seca de folhas na entressafra, $\mathrm{kg} \mathrm{ha}^{-1}$

$\mathrm{MSC}_{\mathrm{ES}}$ - massa seca de colmos na entressafra, $\mathrm{kg} \mathrm{ha}^{-1}$

$\mathrm{MSM}_{\mathrm{ES}}$ - massa seca de material morto na entressafra, $\mathrm{kg} \mathrm{ha}^{-1}$

$$
\mathrm{PROD}_{\mathrm{S}}=\mathrm{MSF}_{\mathrm{S}}+\mathrm{MSC}_{\mathrm{S}}+\mathrm{MSM}_{\mathrm{S}}
$$

em que:

$\mathrm{PROD}_{\mathrm{S}}$ - produtividade total de matéria seca na safra, $\mathrm{kg} \mathrm{ha}^{-1}$ $\mathrm{MSF}_{\mathrm{S}}$ - massa seca de folhas na safra, $\mathrm{kg} \mathrm{ha}^{-1}$

$\mathrm{MSC}_{\mathrm{S}}$ - massa seca de colmos na safra, $\mathrm{kg} \mathrm{ha}^{-1}$

$\mathrm{MSM}_{\mathrm{S}}$ - massa seca de material morto na safra, $\mathrm{kg} \mathrm{ha}^{-1}$

$$
\mathrm{PFC}=\mathrm{MSF}+\mathrm{MSC}
$$

em que:

PFC - produtividade de folhas e de colmos, $\mathrm{kg} \mathrm{ha}^{-1}$

$$
\mathrm{RESS}=\left(\frac{\mathrm{PROD}_{\mathrm{ES}}}{\mathrm{PROD}_{\mathrm{S}}}\right) 100
$$

em que:

RESS - relação entressafra/safra da produtividade de matéria seca, \%

$$
\mathrm{RFC}=\frac{\mathrm{MSF}}{\mathrm{MSC}}
$$

em que:

RFC - relação folha/colmo, adimensional

$$
\mathrm{TL}=\frac{\mathrm{PFC}}{365 \mathrm{NDV}}
$$

em que:

TL - taxa de lotação, UA ha-1

NDV - necessidade diária de volumoso, $\mathrm{kg}$

A necessidade diária de volumoso (NDV) foi considerada igual a $9 \mathrm{~kg}$ de matéria seca (MS), ou seja, 2\% da Unidade Animal (UA $=450 \mathrm{~kg})$.

Essas variáveis foram submetidas à análise de variância a 0,05 de probabilidade e, quando constatadas diferenças significativas, foram submetidas ao teste de média Tukey para irrigação e análise de regressão para doses de nitrogênio.

\section{Resultados e Discussão}

Todas as variáveis responderam de forma linear às doses de nitrogênio e irrigação (Figuras 5 e 6), com exceção da relação folha colmo (RFC), que respondeu apenas à adubação nitrogenada. Os menores valores de tensão de água no solo nas parcelas irrigadas certamente influenciaram esses resultados (Figura 2) ocorrendo no outono, inverno, primavera e verão, 
tensões médias de 6,6, 6,9, 9,3 e 11,3 kPa, respectivamente. Nas mesmas estações e nas parcelas sem irrigação, as tensões médias foram iguais a 32,3, 19,7, 35,9 e $51 \mathrm{kPa}$ superando, em alguns momentos, a marca dos 70 ou $80 \mathrm{kPa}$.

A produtividade total (PROD) cresceu de forma linear quanto à adubação nitrogenada (Figura 5A). Outros autores também observaram esta relação. Para doses variando de 0 a $400 \mathrm{~kg} \mathrm{~N} \mathrm{ha}^{-1}$ no verão, Rocha et al. (2002), em Lavras, MG, e Quaresma et al. (2011), em Cáceres, MT, observaram incremento linear da produtividade do capim Tifton 85 cujo acúmulo de matéria seca variou de 38 a $66,3 \mathrm{~kg} \mathrm{MS} \mathrm{ha-1}^{-1} \mathrm{~d}^{-1} \mathrm{e}$ 50 a 108,3 kg MS ha-1 $\mathrm{d}^{-1}$, respectivamente. Da mesma forma, Alvim et al. (1999) obtiveram, aplicando doses de 0 a $600 \mathrm{~kg} \mathrm{~N}$ $\mathrm{ha}^{-1} \mathrm{ano}^{-1}$, incremento linear de produtividade de capim Tifton 85 em Coronel Pacheco - MG, atingindo $23100 \mathrm{~kg} \mathrm{MS} \mathrm{ha}^{-1} \mathrm{ano}^{-1}$ $\left(63,3 \mathrm{~kg} \mathrm{MS} \mathrm{ha}^{-1} \mathrm{~d}^{-1}\right)$ na maior dose.

$\mathrm{Na}$ ausência de irrigação as produtividades variaram de 7768 a $27826 \mathrm{~kg} \mathrm{MS} \mathrm{ha}^{-1}\left(76,24 \mathrm{~kg} \mathrm{MS} \mathrm{ha}^{-1} \mathrm{~d}^{-1}\right)$ para as doses zero a $60 \mathrm{~kg} \mathrm{~N} \mathrm{ha}^{-1} \mathrm{ciclo}^{-1}$. Com irrigação o incremento foi maior variando de 9210 a $39279 \mathrm{~kg} \mathrm{MS} \mathrm{ha-1}\left(107,61 \mathrm{~kg} \mathrm{MS} \mathrm{ha}^{-1} \mathrm{~d}^{-1}\right)$. As produtividades máximas alcançadas estão de acordo com a literatura que demonstra, para o capim Tifton 85, sem irrigação, um acúmulo anual de matéria de seca compreendido entre 50 e $90 \mathrm{~kg} \mathrm{MS} \mathrm{ha-1} \mathrm{d}{ }^{-1}$ (Alvim et al., 1999; Fagundes et al., 1999; Pinto et al., 2001; Brink et al., 2004; Marsalis et al., 2007), e sob irrigação, entre 105 a $125 \mathrm{~kg} \mathrm{MS} \mathrm{ha}^{-1} \mathrm{~d}^{-1}$ (Marcelino et al., 2003; Fonseca et al., 2007; Bow \& Muir, 2010; Nogueira et al., 2013).

A produtividade com irrigação foi maior tanto na primavera/verão (safra) como no outono/inverno (entressafra) (Figura 5B). Sem irrigação e na dose de $60 \mathrm{~kg} \mathrm{~N}^{-1} \mathrm{a}^{-1} \mathrm{PROD}_{\mathrm{s}}$ e a $\mathrm{PROD}_{\mathrm{ES}}$ atingiram os valores de 24431 e $3395 \mathrm{~kg} \mathrm{MS} \mathrm{ha}^{-1}$, ou seja, $88 \%$ da produtividade anual ocorreram na primavera/ verão. Analogamente, com irrigação, tem-se 30550 e 8730 kg MS ha-1 ${ }^{-1}$ com $78 \%$ da produtividade na safra. A resposta linear à adubação nitrogenada na entressafra difere dos resultados encontrados por Alvim et al. (1999) e Marcelino et al. (2003). No primeiro caso foi observado um comportamento quadrático na entressafra em função das doses de nitrogênio e, no segundo caso, a adubação nitrogenada não afetou a produtividade na entressafra.

A relação de produtividade de entressafra/safra (RESS) decresceu com o incremento das doses de nitrogênio; no entanto, sem irrigação o decréscimo foi menos acentuado (Figura 5C) significando que tanto a irrigação como a adubação nitrogenada são procedimentos importantes para incremento de produtividade porém com um potencial muito maior na safra. Com irrigação, a RESS foi maior, sobremaneira nas doses de 0 e $20 \mathrm{~kg} \mathrm{~N} \mathrm{ha}^{-1}$; na dose de $60 \mathrm{~kg} \mathrm{~N} \mathrm{ha}^{-1}$ por ciclo de pastejo, com e sem irrigação, os valores de RESS foram iguais a 28,5 e $13,8 \%$, respectivamente. Os valores de RESS sob irrigação para diferentes gêneros de capins e diversas regiões, variam de 20 a 55\% (Benedetti et al., 2000; Rassini, 2004; Alencar et al., 2009). Alvim et al. (1999) obtiveram, em Coronel Pacheco, MG, RESS de 29,7\% para capim Tifton 85 sem irrigação. Marcelino et al. (2003) encontraram, em Planaltina, DF, irrigando a partir 35 $\mathrm{kPa}$, RESS de $24,9 \%$.

A produtividade de folhas e colmos (PFC) apresentou comportamento semelhante à PROD (Figura 6A). Na dose de $60 \mathrm{~kg} \mathrm{~N} \mathrm{ha}^{-1}$ a PFC foi de 35051 e $23170 \mathrm{~kg} \mathrm{MS} \mathrm{ha}^{-1}$, com e sem irrigação, respectivamente. Esses valores representam 89 e $83 \%$ da PROD, ou seja, o percentual de material morto foi de 11 e 17\% com e sem irrigação. A média geral do percentual de material morto (MM) com e sem irrigação foi de 13\% ( \pm $4,41)$ e $17 \%( \pm 4,28)$, respectivamente. Carnevalli et al. (2001) obtiveram, conduzindo experimento com Tifton 85 sem irrigação e com pastejo contínuo a $20 \mathrm{~cm}, \mathrm{MM}$ de 14,4\% na primavera e $7,4 \%$ no verão.

A partir da PFC foi estimada a TL (Figura 6B) que atingiu, na dose de $60 \mathrm{~kg} \mathrm{~N} \mathrm{ha}^{-1}$ por ciclo, valores iguais 7 e 10,7 $\mathrm{UA} \mathrm{ha}^{-1}$ $\mathrm{ano}^{-1}$, sem e com irrigação, respectivamente. Na safra essas taxas atingiram 12,6 e 17,2 UA ha ${ }^{-1}$. A TL é corroborada por Azevedo \& Saad (2009), que citam $10 \mathrm{UA} \mathrm{ha}^{-1}$ por ano sob irrigação porém inferior à TL estimada por Aguiar et al. (2006), em Conquista, MG, que obtiveram, sob irrigação, produtividade de Tifton 85 capaz de suportar 13,5 UA ha-1 por ano.

A relação folha colmo (RFC) não foi afetada pela irrigação decrescendo em função das doses de nitrogênio (Figura 6C). Este comportamento pode ter ocorrido em razão da dose 40 $\mathrm{kg} \mathrm{N} \mathrm{ha}^{-1}$ ter sido tomada como referência (visando às mesmas datas de corte para todos os tratamentos) e assim as doses inferiores não estavam ainda com altura adequada de pastejo Além do que a adubação nitrogenada contribui para o maior alongamento do colmo e, portanto, também maior produção de forragem ocorre concomitantemente ao decréscimo na RFC (Oliveira et al., 2011).

A RFC decresceu de 2,65 para 1,95 de 0 a $60 \mathrm{~kg} \mathrm{~N}$ ha $^{-1}$. Quaresma et al. (2011) obtiveram, trabalhando com Tifton 85 em Cáceres, MT, no verão, RFC igual a 1,09, sem diferenças
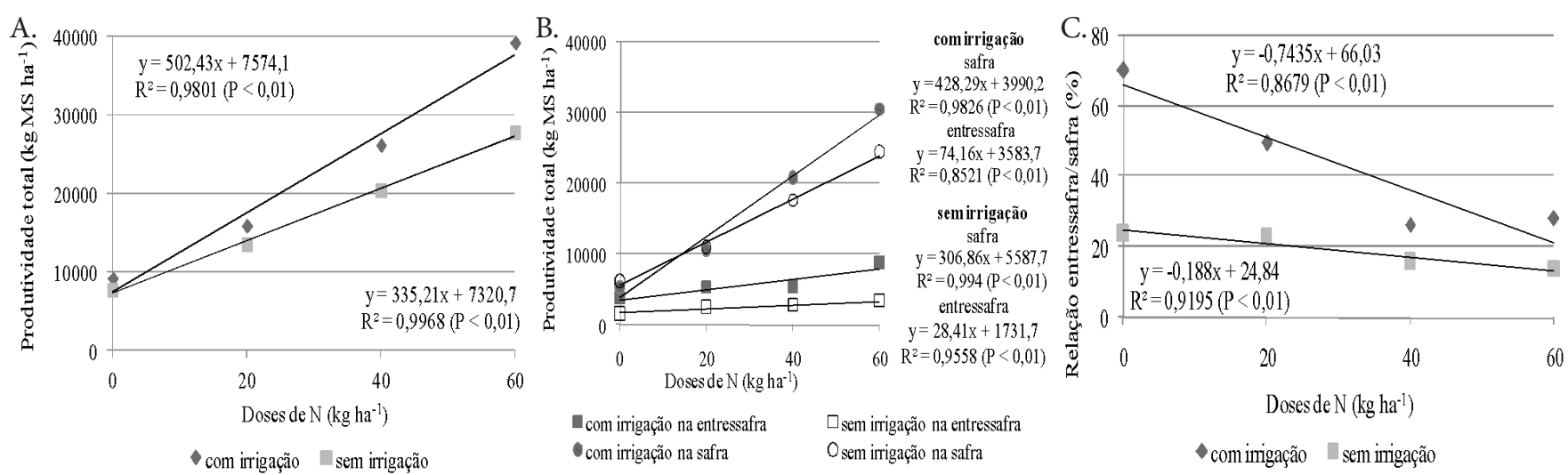

Figura 5. Produtividade de matéria seca total (A), na safra e entressafra (B) e relação entressafra/safra (C) do capim Tifton 85 em função da irrigação e doses de nitrogênio 

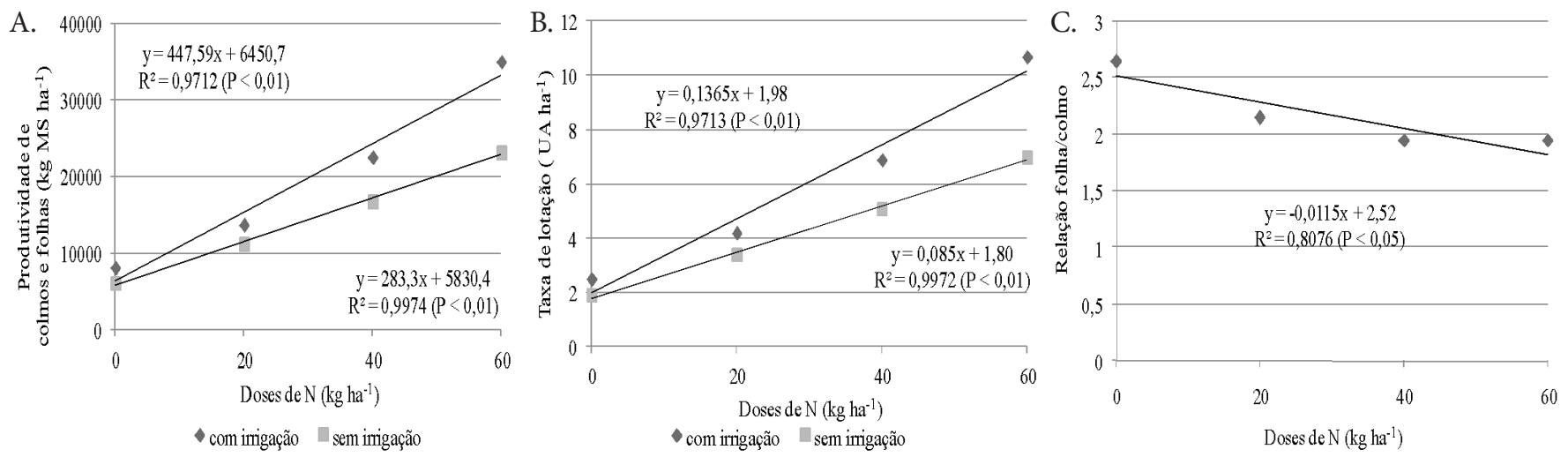

Figura 6. Produtividade de folhas e de colmos (A), taxa de lotação (B) e relação folha/colmo (RFC) do capim Tifton 85 em função da irrigação e doses de nitrogênio

significativas em função da adubação nitrogenada. Oliveira et al. (2011), também encontraram, trabalhando com capim Coastcross no verão, em Viçosa, MG, valores de RFC inferiores decrescendo de 1,15 sem adubação nitrogenada a 0,84 com $400 \mathrm{~kg} \mathrm{~N} \mathrm{ha}^{-1}$.

\section{Conclusões}

1. A irrigação promove maior produtividade de matéria seca de capim Tifton 85 , tanto na safra como na entressafra, maior produtividade de colmos e de folhas e, consequentemente, também maior taxa de lotação.

2. A produtividade de matéria seca do capim Tifton 85 cresce linearmente com as doses de nitrogênio variando de 0 a $60 \mathrm{~kg} \mathrm{~N} \mathrm{ha}^{-1}$ por ciclo de pastejo alcançando 39279 e 27826 $\mathrm{kg} \mathrm{MS} \mathrm{ha-1}$ com e sem irrigação, respectivamente.

3. A relação de produtividade de matéria seca entressafra/ safra decresce com o incremento das doses de nitrogênio atingindo, na dose de $60 \mathrm{~kg} \mathrm{~N} \mathrm{ha}^{-1}$ por ciclo de pastejo, com e sem irrigação, valores iguais a 28,5 e $13,8 \%$, respectivamente.

\section{Literatura Citada}

ABIEC - Associação Brasileira das Indústrias Exportadoras de Carnes. Pecuária brasileira. <http://www.abiec.com.br/3_pecuaria.asp> 22 Jan. 2014.

Aguiar, A. D.; Drumond, L.; Camargo, A.; Minma, J. H.; Scandiuzzi, R.; Resende, J.; Aponte, J. Parâmetros de crescimento de uma pastagem de Tifton 85 irrigada e submetida ao manejo intensivo do pastejo. FAZU em Revista, v.3, p.25-27, 2006.

Alencar, C. A. B.; Cunha, F. F.; Martins. C. E.; Cóser, A. C.; Rocha, W. S. D.; Araújo, R. A. S. Irrigação de pastagem: atualidade e recomendações para uso e manejo. Revista Brasileira de Zootecnia, v.38, p.98-108, 2009. http://dx.doi.org/10.1590/S151635982009001300012

Alvim, M. J.; Xavier, D. F.; Verneque, R. S.; Botrel, M. A. A. Resposta do Tifton 85 a doses de nitrogênio e intervalos de cortes. Pesquisa Agropecuária Brasileira,v.34, p.2345-2352, 1999. http://dx.doi. org/10.1590/S0100-204X1999001200022

Azevedo, L. P.; Saad, J. C. C. Irrigação de pastagens via pivô central na bovinocultura de corte. Irriga, v.14, p.492-503, 2009.

Balieiro Neto, G.; Ferreira, J. J.; Ferreira, M. B. D.; Freire, F. M.; Viana, M. C. M.; Resende, M. Características agronômicas e viabilidade do Tifton 85 irrigado num sistema de produção de leite. Brazilian Journal of Veterynary Research and Animal Science, v.44, p.235-242, 2007.
Benedetti, E.; Demetrio, R. A.; Colmanetti, A.L. Avaliação da resposta da cultivar Tanzânia irrigada em solo de cerrado brasileiro. In: Congresso Panamericano de Leche, 7, 2000, Havana. Anais... Havana: Fepale, 2000. p.27-29.

Bow, J. R.; Muir, J. P. Dynamics of harvesting and feeding Cynodon hybrid Tifton 85 hay of varying maturities to wether kids. Small Ruminant Research, v.93, p.198-201, 2010. http://dx.doi. org/10.1016/j.smallrumres.2010.04.023

Brink, G. E.; Sistani, K.R.; Rowe, D. E. Nutrient uptake of hybrid and common bermudagrass fertilized with broiler litter. Agronomy Journal, v.96, p.1509-1515, 2004. http://dx.doi.org/10.2134/ agronj2004.1509

Carnevalli, R. A.; Silva, S. C.; Fagundes, J. L.; Sbrissia, A. F.; Carvalho, C. A. B.; Pinto, L. F. M.; Pedreira, C. G. S. Desempenho de ovinos e respostas de pastagens de Tifton 85 sob lotação contínua. ScientiaAgricola, v.58, p.7-15, 2001. http://dx.doi.org/10.1590/ S0103-90162001000100002

Corrêa, L. A.; Santos, P. M. Manejo e utilização de plantas forrageiras dos gêneros Panicum, Brachiaria e Cynodon. São Carlos: Embrapa Pecuária Sudeste, 2003. 36p. Documento, 34

Corrêa, L. A.; Santos, P. M. Irrigação de pastagens formadas por gramíneas forrageiras tropicais. São Carlos: Embrapa Pecuária Sudeste, 2006. 6p. Comunicado Técnico, 48

EMBRAPA - Empresa Brasileira de Pesquisa Agropecuária. Sistema brasileiro de classificação dos solos. Brasília: EMBRAPA, 2006. 306p.

Fagundes, J. L.; Silva, S. C.; Pedreira, C. G. S.; Sbrissia, A. S.; Carnevalli, R. A.; Caravalho, C. A. B.; Pinto, L. F. M. Índice de área foliar, interceptação luminosa e acúmulo de forragem em pastagens de Cynodon spp. sob diferentes intensidades de pastejo. Scientia Agricola, v.56, p.1141-1150, 1999. http://dx.doi.org/10.1590/ S0103-90161999000500016

Fonseca, A. F.; Melfi, A. J.; Monteiro, F. A.; Montes, C. R.; Almeida, V. V. D.; Herpin, U. Treated sewage effluent as a source of water and nitrogen for Tifton 85 bermudagrass. Agricultural Water Management, v.87, p.328-336, 2007. http://dx.doi.org/10.1016/j. agwat.2006.08.004

Genuchten, M. T. van. A closed equation for predicting the hydraulic conductivity of unsaturated soils. Soil Science Society of America Journal, v.44, p.892-898, 1980. http://dx.doi.org/10.2136/ sssaj1980.03615995004400050002x

Marcelino, K. R. A.; Vilela, L.; Leite, G. G.; Guerra, A. F.; Diogo, J. M. S. Manejo da adubação nitrogenada de tensões hídricas sobre a produção de matéria seca e índice de área foliar de Tifton 85 cultivado no cerrado. Revista Brasileira de Zootecnia, v.32, p.268275, 2003. http://dx.doi.org/10.1590/S1516-35982003000200004 
Marsalis, M. A.; Allens, V. G.; Brown, C. P.; Green, C. J. Yield and nutritive value of forage bermudagrasses grown using subsurface drip irrigation in the southern high plains. Crop Science, v.47, p.1247-1256, 2007. http://dx.doi.org/10.2135/ cropsci2006.06.0399

Nogueira, S. F.; Pereira, B. F. F.; Gomes, T. M.; Paula, A. M.; Santos, J. A.; Montes C. R. Treated sewage effluent: agronomical and economical aspects on bermudagrass production. Agricultural Water Management, v.116, p.151-159, 2013. http://dx.doi. org/10.1016/j.agwat.2012.07.005

Oliveira, M. A.; Pereira, O. G.; Ribeiro, K. G.; Santos, M. E. R.; Chizzotti, F. H. M.; Cecon, P. R. Produção e valor nutritivo do capim-coastcross sob doses de nitrogênio e idades de rebrotação. Arquivo Brasileiro de Medicina Veterinária e Zootecnia, v.63, p.694-703, 2011. http://dx.doi.org/10.1590/ S0102-09352011000300022
Pinto, L. F. M.; Silva, S. C.; Sbrissia, A. F.; Carvalho, C. A. B.; Carnevalli, R. A.; Fagundes, J. A.; Pedreira, C. G. S. Dinâmica do acúmulo de matéria seca em pastagens de Tifton 85 sob pastejo. Scientia Agricola, v.58, p.436-447, 2001.http://dx.doi.org/10.1590/S0103-90162001000300001 Quaresma, J. P. S.; Almeida, R. G.; Abreu, J. G.; Cabral, L. S.; Oliveira, M. A.; Carvalho, D. M. G. Produção e composição bromatológica do capim Tifton 85 submetido a doses de nitrogênio. Acta Scientiarum Animal Science, v.33, p.145-150, 2011.

Rassini, J.B. Período de estacionalidade de produção de pastagens irrigadas. Pesquisa Agropecuária Brasileira, v.39, p.821-825, 2004. http://dx.doi.org/10.1590/S0100-204X2004000800014

Rocha, G. P.; Evangelista, A. R.; Lima, J. A.; Rosa, B. Adubação nitrogenada em gramíneas do gênero Cynodon. Ciência Animal Brasileira, v.3, p.1-9, 2002.

Rodrigues, B. H. N.; Magalhães, J. A.; Lopes, E. A. Irrigação e adubação nitrogenada em três gramíneas forrageiras. Revista Ciência Agronômica, v.36, p.274-278, 2005. 